\title{
The Skype solution
}

$\mathrm{M}$ any patients would balk at the notion of going to the doctor - on their computers. And many family doctors are skeptical that medicine by Skype is effective or can even result in a complete diagnosis of a patient's condition.

Yet logging in and having an online video chat with a doctor is becoming ever more common in the United States. Insurance companies are starting to pay doctors for such online consultations. BCC Research, a market research firm based in Wellesley, Massachusetts, earlier this year predicted that the telehome medicine market, which includes all medical products and services provided in patients' homes via teletechnologies, will increase from US\$2.9 billion in 2010 to US\$7.9 billion in 2015 .

That doesn't surprise Dr. Jay Sanders, the so-called "father of telemedicine," president and CEO of the Global Telemedicine Group and adjunct professor of medicine at the Johns Hopkins University School of Medicine in Baltimore, Maryland. "Patients don't have to leave work and they save in transportation costs. Those costs alone make [booking an online appointment] worth it," he says.

Such savings, and convenience, appear to be the primary appeals of video chat medicine.

Patients can log in 24/7 and usually get access to a doctor within 10 minutes, says Randy Parker, CEO of the MDLiveCare, an interactive medical consultation firm that says it has connected more than 250000 Americans to doctors in their home states (as required by regulation).

As a consequence, patients are more likely to seek medical treatment before their conditions necessitate visits to emergency departments, "which is much more expensive," adds Parker, who notes that video chat medicine has gained legitimacy to the point where several major American medical insurers now fully or partially cover a select number of online consultations annually.

Patients without medical insurance

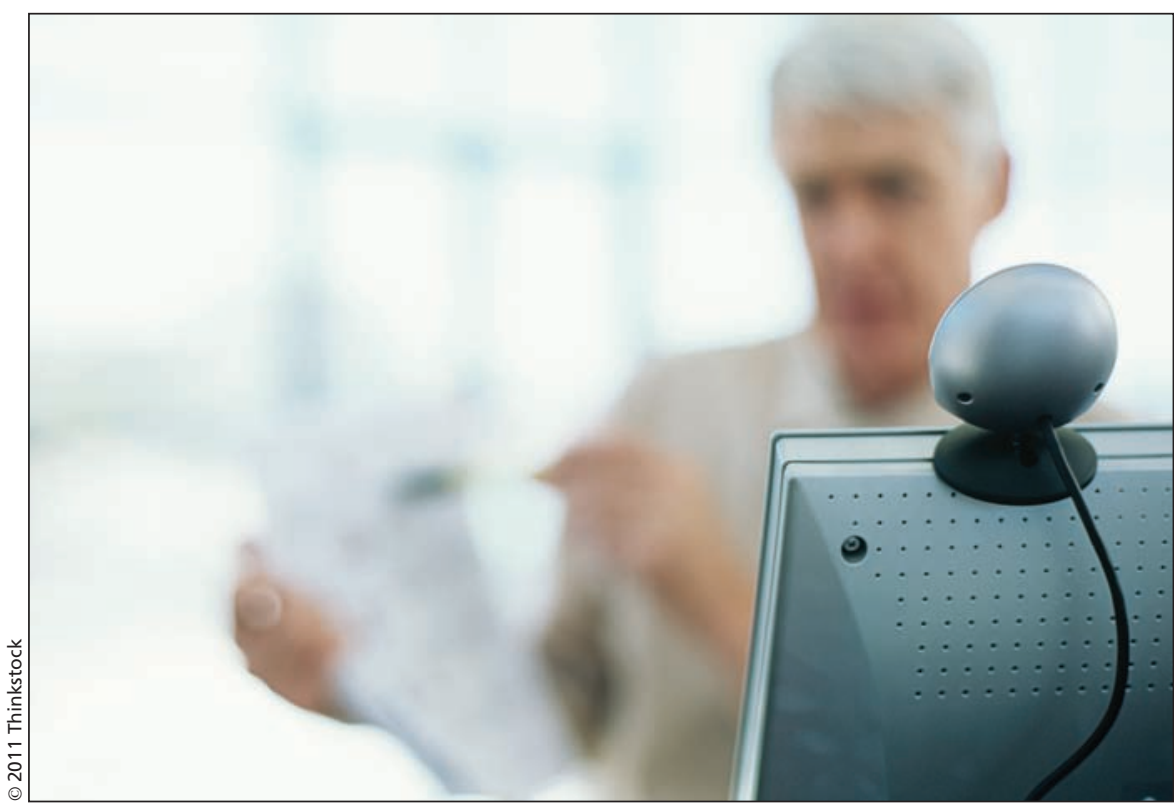

The webcam is becoming an important tool in medicine in the United States as more doctors choose to communicate with patients via online video chat services.

pay \$US50 for a 10-minute online consultation arranged by MDLiveCare. That's comparable to the charges levied by other firms. SwiftMD, for example, charges $\$ 60$ per consultation.

The firms and doctors can order prescriptions and direct patients to affiliated labs for tests. Parker says the most commonly treated conditions include fevers, allergies, urinary tract infections, acne and sinus infections. But even addictions and anxiety orders are treated, he adds.

Many family doctors, though, are wary of medicine by Skype.

Dr. Danielle Ofri, associate professor of medicine at the New York University School of Medicine, worries that online doctors don't get the full picture of a patient's health. "So much in the connection with the patient is nonverbal," he says, arguing that only through cues such as body language and facial expressions, which often aren't as easy to interpret online, can physicians get a full sense of the patient's concerns and anxieties, or other underlying problems.

"Sometimes patients come in and they may appear to have a straightforward ear infection but there's also domestic violence or depression at home," says Ofri. "I would worry that things could be missed [in video consultations]."

The US government also seems to be taking a more prudent approach to telehome services. In March, the Centers for Medicare and Medicaid Services unveiled revisions to regulations for payment policies (http://edocket.access .gpo.gov/2011/pdf/2011-7880.pdf). But the proposals did not include waiving telehealth restrictions on Accountable Care Organizations (coordinated groups of health care providers who contract with Medicare and Medicaid to provide services). Currently, online consultations are covered for patients in rural areas but not those in urban centres. Nor are such consultations covered for smoking cessation or diabetes self-management.

The American Telemedicine Association had been hoping the federal agency would loosen the restrictions, which the association calls "formidable." - Wendy Glauser, Toronto, Ont.

CMAJ 2011. DOI:10.1503/cmaj.109-3928 